\title{
Study on the measurement of environmental finance accounting in China
}

\author{
Jiangxia Yu ${ }^{1}$, Xiaojun Lu ${ }^{2, *}$, Dingqing $\mathrm{Li}^{3}$, Lingzhi $\mathrm{Tan}^{3}$ \\ ${ }^{1}$ Chongqing College of Chemical Engineering, Chongqing, 400000, China \\ ${ }^{2}$ Harbin University of Commerce, 150028, China \\ ${ }^{3}$ Chongqing Technology and Business University, Chongqing, 400000, China
}

Keywords: Environmental finance accounting; Environmental management accounting; Environmental finance report; Efficiency coefficient method

\begin{abstract}
Based on the analysis of the limitations in the development of environmental accounting in China, this paper proposes that the development of environmental financial accounting practice in China should be promoted first, and the concept of the choice of measurement method of environmental financial accounting should be considered. From the perspective of efficiency coefficient method, the paper aims to transform the complex multi-dimensional measurement space into one-dimensional measurement space, transition from a variety of measurement units to a single measurement unit, and crack the bottleneck of confirmation and measurement of environmental accounting elements.
\end{abstract}

\section{解决我国环境财务会计计量问题的探究

\author{
余江霞 ${ }^{1}$, 鲁骕军 ${ }^{2,}{ }^{*}$, 李定清 ${ }^{3}$, 谭灵芝 ${ }^{3}$ \\ ${ }^{1}$ 重庆化工职业学院, 重庆 400000 \\ 2哈尔滨商业大学，哈尔滨 150028 \\ ${ }^{3}$ 重庆工商大学，重庆 400000
}

关键词: 环境财务会计;环境管理会计;环境财务报告;功效系数法

摘 要: 本文通过对我国环境会计发展过程中的局限性分析, 提出应首先推进我国环境财务 会计实务的发展, 需考虑环境财务会计计量方法选择的理念。从功效系数法角度进行改进, 以期将复杂的多维计量空间转化为一维计量空间, 从多种计量单位过渡到单一计量单位, 破 解环境会计要素的确认与计量的瓶颈。

\section{1. 引 $\square$ 言}

近年来，环境会计问题逐渐从学者研究视野进入实质性操作阶段，我国在环境会计基本理 论框架、要素确认、环境信息披露等方面取得了一些研究成果，但与西方发达国家相比，我 国的环境会计理论和实践研究尚处起步阶段，仍存在自成体系形成自我边界限制、环境管理 会计研究较少涉猎、亟需多方合力与多方协同合作等发展过程中的局限，本着反映和控制社 会环境资源，改善社会环境与资源，实现经济效益、生态效益和社会效益的同步最优化的基 本目标, 考虑环境财务会计计量方法选择, 从功效系数法角度进行改进, 以期将复杂的多维 计量空间转化为一维计量空间, 从多种计量单位过渡到单一计量单位, 破解环境会计要素的 确认与计量的瓶颈。 


\section{2. 环境会计发展过程局限性}

\section{1 自成体系形成自我边界限制}

我国环境会计理论研究与实践起步较晚, 某种程度而言相对封闭, 我国环境会计理论研究 与实践水平与国际交流较少, 针对性地吸收和借鉴西方国家理论研究与实践经验成果途径有 限, 多数研究停留在文献研究与学界研究, 导致大部分理论研究水平较低, 研究内容重复度 高, 虽有部分学者逐渐吸收和借鉴西方国家的先进理论与实践经验, 但该部分环境会计理论 与实践研究多基于西方环境会计的发展历史、现实状况和未来趋势而产生，其学科定位、涵 盖范围和应用领域在某种程度上与我国环境会计发展容易出现偏差, 开展基于我国背景下的 环境会计发展问题与计量研究有利于开拓我国环境会计研究的边界限制。

\section{2 环境管理会计研究较少涉猎}

环境会计分为环境财务会计和环境管理会计。环境管理会计主要为企业内部环境管理服 务, 为企业环境影响决策提供帮助的同时降低环境管理成本, 为提高环境绩效献计献策, 某 种程度相当于传统会计的管理会计。环境财务会计的目的是明确掌握企业因生产活动而产生 的环境负荷情况, 将该情况连同企业采取的环保措施及其成效向外界进行系统地报告, 某种 程度相当于传统会计的财务会计。环境管理会计内容灵活多样，可以因使用目的、分析方法、 计量方法等的不同而进行灵活选择，为环境财务会计的确认、计量方法的选择提供丰富的理 论和实践方法, 具有多样性、灵活性和艺术性的特点。我国现有环境会计研究主要集中在环 境财务会计领域, 对环境管理会计较少涉猎, 研究进展相对缓慢, 环境财务会计的发展受到 较大限制，环境会计的整体发展较为滞后。

\section{3 亟需多方合力与多方协同合作}

我国环境会计理论研究与实践研究取得的重大理论创新和实用价值的成果数量较少, 环境 会计研究中研究人员多数力量分散, 研究不能形成合力, 个人单打独斗的局面较多, 致使环 境会计理论研究与实践的研究效果不明显。环境会计问题在现有复杂的经济环境和背景下具 有跨界广、难点多和难度大等特征, 通常需要不同学科背景的研究者通力合作, 才能把握问 题的本质, 针对性的提出问题的解决思路。若需将西方国家生态会计理论的研究成果纳入我 国环境财务会计中，则需要学界、管理界和政界的多方努力。

\section{3. 环境财务会计计量方法选择}

影响环境财务会计从理论走向实践的因素较多，如环境财务会计方法体系的多元化,核算 对象的复杂化,尤其是计量环节上的瓶颈,使得当前环境财务会计缺乏与实务相结合的理论支 点, 导致我国至今无法规范环境财务会计实务。因此, 环境财务会计发展的关键是解决其计量 的问题。其解决途径包括:

\section{1 以会计准则规范环境财务会计}

西方国家建立的会计准则按照要素和经济事项进行分别制定，采用该类方法的优点是能够 借助会计要素和经济业务的划分，将要素和业务涉及的相关定义、特征、计量和披露等阐述 得更加全面和清晰, 使之逻辑思维更加缜密。如若出现某项经济业务随经济环境有所改变时, 可以通过修改某项具体准则进行代替，该种方式能够有效的降低修改业务的成本，同时兼具 灵活和便捷的特点。

\section{2 关注环境财务的报告内容}

环境财务报告由环境保全成本、环保效果和伴随环保对策的经济效益三部分组成。环境保 全成本指用于防止、控制或避免环境负荷的产生, 消除环境影响, 对引起的环境危害进行补 
救或有助于上述工作得以进行的投资和费用, 以货币单位计量。环保效果指用于防止、控制 或避免环境负荷的产生, 消除环境影响, 对引起的环境危害进行补救或有助于以上工作开展 所取得的成效, 以物理单位计量, 主要内容比如生产经营过程中能源、资源使用量减少, 排 入环境中各种废弃物的减少量等, 可以将其分类与环境保全成本的分类进行对应。伴随环保 对策的经济效益指推行环保对策给企业带来的经济效益, 以货币单位计量, 根据基础数据的 可靠程度可以分为实际效益和推测效益。实际效益是依据确丵的证据计算的经济效益, 由收 益和节约的费用两部分组成，推测效益是通过假设性计算的经济效益。

现有的理论研究实践将环境保全成本和实际效益包含在环境财务报告中，但环境财务报告 是否应涵盖环保效果和推测效益还存在较多分歧。从货币计量的前提条件出发, 我国环境财 务会计的主流观点是环境财务报告应以环境保全成本和实际效益为主, 但从西方国家学术界 和实务界的发展趋势角度, 将物理计量手段一并纳入环境财务会计成为较为共识的一种观 点, 按照此观点, 环境保全成本、伴随环保对策的经济效益和环保效果等内容应全部纳入环 境财务报告中, 但应将推测效益排除环境财务报告。相比较于实际效益, 推测效益的或然性 小, 不够明确, 包含推定因素, 若将其包括在环境财务会计的核算范围内将有损于财务会计 中的谨慎性原则, 推测效益是经营管理的重要信息, 可以在环境管理会计中予以反映。从受 托责任观出发, 环保效果应是环境财务报告的重点披露内容, 其与民众环境资产保全关系密 切, 同时能够直接体现企业环境绩效, 能够直接向外界予以反映, 外界对该项指标也十分关 注。

\section{3 使用功效系数法}

环境财务报告中环境保全成本和伴随环保对策的经济效益均能以货币单位计量, 在确认和 计量等方面均不存在问题, 而环保效果采用物理单位为计量单位, 对物理单位的评测与反映 能够直接影响企业披露的环境报告, 进而对环境财务会计实务造成影响。因此, 在环境财务 报告中表述环保效果时, 须在物理单位的基础之上构建新的一种度量方式, 该度量方式须满 足综合性、易读性和与货币计量过渡性的三个条件, 即功效系数法。功效系数法, 能够较好 地反映私人成本与社会成本的关系, 提供的环保效果会计信息质量较高, 便于找寻综合功效 系数与经济效果之间的关系。每个会计主体在进行自身经济活动时都会与其它主体发生一定 的经济关系，同时还会对其他主体或周围社会产生影响，具备一定的经济外部性特征。

从反映私人成本与社会成本的关系角度, 若出现私人成本大于社会成本时, 企业生产经营 活动会对环境造成不良影响, 造成外部不经济现象。由于外部不经济现象难以通过交易价格 得到反映, 使得私人成本与社会成本难以直接计算。功效系数虽然不能计算私人成本和社会成 本，但能够反映两者间的关系。当功效系数大于等于 100 时, 企业生产经营活动对环境的影响 是友好的, 表现出私人成本大于等于社会成本, 即外部经济现象, 当功效系数等于60-100时, 企业生产经营活动对环境的影响是中性的, 表现出私人成本大致等于社会成本。当功效系数 小于60时, 企业的生产经营活动对环境的影响不友好, 表现出私人成本小于社会成本, 即外 部不经济现象。从提供环保效果和会计信息质量角度, 会计信息质量特征应符合客观性、相 关性、可比性、一贯性、及时性和明晰性等原则, 以国家制定的环保标准和企业实际排污水 平为计算依据, 具有客观性、可比性和一贯性等特点, 由于功效系数法涉及企业排放的所有 污染物和治理效果等诸多内容, 内容与内容间集聚正向的相关性, 该方法计算过程简单, 易 于理解, 结果清晰明了。从便于找寻综合功效系数与经济效果之间的关系角度, 借助计量经 济学方法, 将众多变量化为一个变量, 将反映企业环保效果与经济效果间关系的模型简单化, 为最终的功效系数转换为货币单位创造条件。

根据功效系数法的基本原理

设有 $\mathrm{P}$ 个目标 $f_{1}(x), \cdots \cdots, f_{k}(x), f_{k+1}(x), \cdots \cdots, f_{p}(x)$, 其中前 $\mathrm{k}$ 个目标越小越好, 后 $\mathrm{p}-\mathrm{k}$ 个目标越 大越好。针对各目标量纲情况的不同, 通过引用功效系数 $d_{j}$ 打分的方式判断各个目标函数值 
的好坏。 $d_{j}$ 的取值区间为 $[0,1]$, 目标函数值最好时令 $d_{j}=1$; 最差时令 $d_{j}=0$ 。 假定当 $j=1,2,3 \cdots, \mathrm{k}$ 时的目标函数值越小越好, 可以假设

$$
\begin{gathered}
d_{j}=\left\{\begin{array}{lll}
1 & \text { 当 } & f_{j}=f_{j \text { min }} \\
0 & \text { 当 } & f_{j}=f_{j \max }
\end{array}\right. \\
\frac{f_{j}(x)-f_{j \min }}{f_{j \max }-f_{j \min }}=\frac{d_{j}-1}{0-1} \\
d_{j}=1-\frac{f_{j}(x)-f_{j \min }}{f_{j \max }-f_{j \min }} \quad j=1,2,3 \cdots, k
\end{gathered}
$$

当 $j=k+1, k+2, \cdots, p$ 时, 可令

$$
d_{j}=\left\{\begin{array}{lll}
1 & \text { 当 } & f_{j}=f_{j \max } \\
0 & \text { 当 } & f_{j}=f_{j \min }
\end{array}\right.
$$

得到

$$
d_{j}=\frac{f_{j}(x)-f_{j \min }}{f_{j \max }-f_{j \min }} \quad j=k+1, k+2, \cdots, p
$$

实际运用中按照功效系数法的思想, 采用改进后的功效系数公式如下

$$
y_{i}=\frac{x_{i}-x_{i}^{(s)}}{x_{i}^{(h)}-x_{i}^{(s)}} * 40+60
$$

或

$$
y_{i}=100-\frac{x_{i}^{(h)}-x_{i}}{x_{i}^{(h)}-x_{i}^{(s)}} * 40
$$

式中: $x_{i}$ 为统计指标的实际观测值; ${ }_{i}$ 为对应于 $x_{i}$ 的评价分数值; ${ }^{(s)}$ 为第 $\mathrm{i}$ 个指标的不容许 值; ${ }_{i}^{(h)}$ 为第 $\mathrm{i}$ 个指标的满意值。

按改进后的功效系数法公式计算, 当企业第 $\mathrm{i}$ 种污染物排放水平达到相关标准时, 分区间值 为60-100, 与百分制中及格以上的评价标准一致，由此算出企业每一项污染物排放的分值后， 将全部指标的评价分数值进行简单平均或加权平均, 求出综合评价分值, 运用综合评价分值, 则可对企业环保效果做出全面评价和综合比较。

\section{4. 结 论}

从新古典经济学角度, 消费者若希望实现效用最大化, 其决策须建立在现有商品价格基础 之上, 货币单位是衡量价格的基础, 在环境财务会计计量领域, 尽管多数声音赞同采用多种 计量单位的权益方式, 但随着环境财务会计计量的发展, 采用货币计量仍为最终发展的方向, 从多种计量单位过渡到单一计量单位期间, 采用功效系数法作为度量环境效用的表现形式, 可以将复杂的多维计量空间转化为一维计量空间, 将复杂的问题简单化, 更有利于计量问题 的解决。 


\section{[参 考 文 献]}

[1] 杨世忠. 环境会计主体:从“以资为本”到“以民为本”[J] . 会计之友，2016，(1)：14-16. [2] 王秋洋. 上市公司环境会计信息披露三方博弯分析一基于利益相关者的视角 [J]. 财会通 讯, 2015, (36) : 10-13.

[3] 卢秋声, 干胜道. 基于利益相关者预期的企业环境会计信息披露研究 [J] . 广西社会科学, 2015, (11) : 76-83.

[4] 李君, 黄林. 制度环境、会计信息质量与公司投资效率 $[\mathrm{J}]$. 会计之友, 2015，(4)：66 -70 .

[5] 刘晓华, 王华. 市场环境、会计准则国际趋同与会计信息质量[J]. 山西财经大学学报, 2015, (7) : 111-123.

[6] 张以宽, 孙兴华, 方宇. 关于加强环境会计与环境审计研究的几个问题 $[\mathrm{J}]$. 中国内部审 计, 2014, (11) : 95-96.

[7] 韩冬芳. 我国环境会计体系建设顶层设计问题研究[J]. 会计之友, 2014, (17) : 16-18.

[8] 周守华, 陶春华. 环境会计:理论综述与启示 $[J]$. 会计研究, 2012, (2) : 3-10.

[9] 梁小红. 国外环境会计理论研究视域、逻辑及启示 $[\mathrm{J}]$. 福建论坛(人文社会科学版), 2012, (9) : $27-33$. 